\title{
Unraveling the Wheat Stem Rust Infection Process on Barley Genotypes Through Relative qPCR and Fluorescence Microscopy
}

\author{
J. D. Zurn, S. Dugyala, P. Borowicz, R. Brueggeman, and M. Acevedo
}

First, second, fourth, and fifth authors: Department of Plant Pathology, and third author: Department of Animal Sciences, North Dakota State University, Fargo 58108.

Accepted for publication 5 January 2015.

\begin{abstract}
Zurn, J. D., Dugyala, S., Borowicz, P., Brueggeman, R., and Acevedo, M. 2015. Unraveling the wheat stem rust infection process on barley genotypes through relative qPCR and fluorescence microscopy. Phytopathology 105:707-712.

The infection process of wheat stem rust (Puccinia graminis $\mathrm{f}$. $\mathrm{sp}$. tritici) on barley (Hordeum vulgare) is often observed as a mesothetic infection type at the seedling stages, and cultivars containing the same major resistance genes often show variation in the level of resistance provided against the same pathogen race or isolate. Thus, robust phenotyping data based on quantification of fungal DNA can improve the ability to elucidate host-pathogen interaction, especially at early time points of infection when disease symptoms are not yet evident. Quantitative real-time polymerase chain reaction (qPCR) was used to determine the amount of fungal DNA relative to host DNA in infected tissue, providing new insights about fungal development and host resistance during the infection process in this pathosystem. The stem rust susceptible 'Steptoe', resistant cultivars containing only Rpg 1

('Beacon', 'Morex', and 'Chevron'), and the resistant line Q21861 containing Rpg1 and the rpg4/Rpg5 complex were evaluated using the traditional 0-to-4 rating scale, fluorescence microscopy, and qPCR. Statistical differences $(P<0.05)$ were observed in fungal development as early as $24 \mathrm{~h}$ postinoculation using the qPCR assay. Fungal development observed using fluorescence microscopy displayed the same hierarchal ordering observed using the qPCR assay. The fungal development occurring at 24 and $48 \mathrm{~h}$ postinoculation was vastly different than what was expected using the traditional disease phenotyping methodology; with Steptoe appearing more resistant than the barley lines harboring the known Rpg1 and rpg4/Rpg5 resistance complex. These data indicate potential early prehaustorial resistance contributions in a cultivar considered susceptible based on infection type. Moreover, the temporal differences in resistance suggest pre- and post-haustorial resistance mechanisms in the barley-wheat stem rust infection process, indicating potential host genotype contributions related to basal defense during the wheat stem rust infection process.
\end{abstract}

In the early 20th century, many epidemics of wheat stem rust, caused by Puccinia graminis f. sp. tritici Erikss. \& Henning, caused large yield losses for common wheat (Triticum aestivum L.), durum wheat (T. turgidum subsp. durum (Desf.) Husn.), and barley (Hordeum vulgare L.). Since then, $P$. graminis has been primarily managed through the removal of its alternate host, the common barberry (Berberis vulgaris L.), and the introduction of resistant wheat and barley cultivars (17). The barberry eradication program in the United States was particularly effective by eliminating the sexual stage of $P$. graminis (17). The removal of the pathogen's sexual stage precludes genetic recombination, dramatically slowing the emergence of new races and allowing for the prediction of race prevalence on a yearly basis (29).

The distribution of resistant barley varieties to farmers has mitigated damage caused by $P$. graminis f. sp. tritici since the $1940 \mathrm{~s}$ (34). This is mainly due to the incorporation of the gene Rpgl, which was acquired from 'Kindred' in the United States and 'Peatland' in Canada, and is now fixed in all Midwestern barley cultivars (6). Rpg1 provides the majority of resistance to endemic races of the stem rust pathogen in the Midwestern United States and Prairie Provinces of Canada (6,9). Furthermore, significant effort has been devoted toward the characterization of Rpgl due to its longstanding success as a durable resistance gene. The emergence of the highly virulent Ug99 lineage in Eastern Africa in 1999 and races virulent on Rpgl from the Pacific Northwest in 1989 and the ensuing identification of the rpg4/Rpg5 resistance complex

Corresponding author: M. Acevedo; E-mail address: Maricelis.Acevedo@ndsu.edu

http://dx.doi.org/10.1094/PHYTO-09-14-0251-R

(C) 2015 The American Phytopathological Society effective against these races have warranted a need to better understand the barley-wheat stem rust pathosystem $(26,34,37)$.

Rpgl-containing cultivars often exhibit varying resistant infection types due to their unique genetic backgrounds $(21,34,39,44)$. The quantitative interactions of genes influencing this phenomenon are not currently fully understood. The use of a traditional 0-to-4 scoring scale on barley seedlings is often complicated by a mesothetic reaction to many pathotypes of $P$. graminis $(11,34,36)$. Quantification of fungal DNA by quantitative real-time polymerase chain reaction (qPCR) is an effective way to overcome the limitations of evaluating host-pathogen interaction solely based on categorical data collected using the 0-to-4 scale. This method also allows for a more robust assessment of temporal interactions occurring during the infection process because of the ability to assess early stages of the infection process.

The use of absolute qPCR for resistance phenotyping has been used successfully for other cereal pathosystems, such as crown rust (caused by Puccinia coronata f. sp. avenae P. Syd. \& Syd.) in Avena sativa L. (15). The process described by Jackson et. al. (15) involved a series of laborious measurements which led to the development of a relative assay which overcame the measurement issues by using specific primer and probe combinations for a reference gene instead of relying on dry weight measurements (2). The use of relative qPCR assays has been shown to provide an accurate way to characterize a cultivar's phenotype, as well as provide information about cultivar resistance prior to the appearance of symptoms in numerous pathosystems $(2-4,14,25,27)$. Additionally, relative qPCR has been successfully utilized to map quantitative trait loci (QTL) associated with adult partial resistance (1).

Because disease symptoms are not visible until 8 or 9 days after inoculation, it is difficult to determine how the wheat stem rust 
infection progresses during early stages of development. Currently, the best methodology for assessing the infection process at early stages is through the use of fluorescence microscopy. Fluorescence microscopy has been used to evaluate the infection process of wheat rusts; however, the methodology surrounding sample preparation is laborious for large sample sizes $(16,18,30,31,42)$ Thus, the objective of this project was to develop a qPCR assay to assess the infection process at multiple time points, determine the accuracy of the qPCR assay at early stages using fluorescence microscopy and late stages using traditional phenotyping, and evaluate cellular and physical differences in host resistance at the early stages of the infection process.

\section{MATERIALS AND METHODS}

Host and inoculum. Four barley cultivars ('Steptoe', 'Beacon', 'Morex', and 'Chevron') and the line Q21861 were grown in a completely randomized design with an experimental unit consisting of two plants. The experimental units were replicated four times for each time point to be evaluated for the qPCR assay. The experiment was performed twice to account for biological and experimental variation. An independent set of the same varieties consisting of 12 replications of one plant per genotype per time point was also planted for evaluation using fluorescence microscopy. Steptoe does not contain any previously characterized resistance genes to $P$. graminis; Beacon, Morex, and Chevron have the major resistance gene Rpgl, which is effective against $P$. graminis f. sp. tritici race MCCFC used in this study; and Q21861 contains both Rpg1 and the rpg4/Rpg5 resistance complex, which is also effective against $P$. graminis f. sp. tritici race MCCFC $(7,21,22)$. Plants were grown in a growth chamber with a day-andnight cycle of 14 and $10 \mathrm{~h}$ and a temperature of 22 and $18^{\circ} \mathrm{C}$, respectively. Seven days after planting, the seedlings were inoculated via a spray inoculation with $P$. graminis $\mathrm{f}$. sp. tritici race MCCFC at a concentration of $7 \times 10^{6}$ urediniospores $/ \mathrm{ml}$ of Soltrol 170 (Chevron Phillips Chemical Company LLC, Woodlands, TX).

Sample handling, phenotypic evaluation, and standard development for qPCR. Four tissue samples were collected for the qPCR assays at five time points for each barley genotype, reflecting a natural progression of the infection process. The temporal points for the first experiment included prior to inoculation, immediately after inoculation, $48 \mathrm{~h}$ postinoculation (HPI), 6 days postinoculation (DPI), and 14 DPI. The temporal points for the second experiment included prior to inoculation, immediately after inoculation, 24 and $48 \mathrm{HPI}$, and 6 DPI. At each time point, $5 \mathrm{~cm}$ of tissue was collected from the center of the leaves and stored in a 2-ml microtube at $-80^{\circ} \mathrm{C}$ until all samples were collected. At 12 DPI, all plants were scored prior to tissue collection using a 0-to-4 scale and the median infection type observed was used to establish resistance levels to $P$. graminis f. sp. tritici race MCCFC for each cultivar. The 0-to-4 scale used was modified from the scale used to evaluate $P$. graminis f. sp. tritici infection in wheat (33). In the scale, an infection type of 0 indicates the absence of symptoms, a fleck (;) indicates necrosis in the absence of visual uredinial pustules, 1

TABLE 1. Barley ubiquitin and Puccinia graminis f. sp. tritici internal transcribed spacer primer and probe sequences

\begin{tabular}{ll}
\hline Primer/probe & \multicolumn{1}{c}{ Sequence $\left(5^{\prime}-3^{\prime}\right)$} \\
\hline Hvubi-F1 & ACTACAACATCCAGAAGGAGTCCAC \\
Hvubi-R1 & GTCGAAGTGGTTGGCGGCCATGAAGGTC \\
Hvubi VIC & VIC-CGCCAAGAAGCGCAAGAAGAAGACGTACACC- \\
& MGBNFQ \\
ITS1rustF10d & TGAACCTGCAGAAGGATCATTA \\
ITS1rustR3c & TGAGAGCCTAGAGATCCATTGTTA \\
Pg FAM 1 & 6FAM-TTGTGGCTCGACTCTCTTATAAACCAAACC- \\
& MGBNFQ \\
\hline
\end{tabular}

indicates a pustule surrounded by necrosis, 2 indicates a pustule surrounded by chlorosis, 3 is defined as a round pustule without chlorosis, and 4 is defined as a large and often diamond-shaped pustule. Additionally, a plus (+) or minus (-) sign was used to indicate increased or decreased sporulation that deviate from what is typically observed for an infection type, and a mesothetic reaction was denoted by $\mathrm{X}$. In cases where multiple infection types were observed on a leaf, each infection type was recorded in order of frequency observed on the leaf. Infection types of 0 , fleck (;), 1, 2, and $\mathrm{X}$ are considered resistant and infection type of 3 and 4 are susceptible.

DNA for the standards and samples was extracted using a modified cetyltrimethylammonium bromide method (38). Host and pathogen standards for this experiment consisted of DNA extracted from Steptoe barley and $P$. graminis f. sp. tritici race MCCFC urediniospores, respectively. Five-point serial host and pathogen standards were developed by diluting genomic DNA to concentrations ranging from 200 to $2.47 \mathrm{ng} / \mu \mathrm{l}$ along a threefold serial dilution in accordance with the MIQE guidelines (8).

Evaluation of the stem rust infection progression via qPCR. Fungal DNA was amplified utilizing a previously developed hydrolysis probe and species-specific markers (5). Primers and hydrolysis probes for the reference gene (Table 1) were developed based on a barley ubiquitin gene (GenBank accession M60175) identified by Rostoks et al. (32). Primers were obtained from Sigma-Aldrich (St. Louis, MO) and hydrolysis probes were obtained from Life Technologies (Carlsbad, CA). The expected amplicon size is 242 and 270 bp for the barley (Hvubi-F1 and Hvubi-R1) and rust primers (ITS1rustF10d and ITS1rustR3c), respectively. Amplicon size was confirmed through conventional PCR and agarose gel electrophoresis. Reactions were completed at a volume of $20 \mu \mathrm{l}$ containing $1 \times$ PCR buffer, $2.5 \mathrm{mM} \mathrm{MgCl}$, $187.5 \mu \mathrm{M}$ dNTPs, $500 \mathrm{nM}$ primer, $60 \mathrm{ng}$ of DNA, and 1 unit of GoTaq (Promega Corporation, Madison, WI). Amplification was performed under the following conditions: initial denaturation at $94^{\circ} \mathrm{C}$ for $5 \mathrm{~min}$; followed by 40 cycles of $30 \mathrm{~s}$ of denaturation at $94^{\circ} \mathrm{C}$, a $60^{\circ} \mathrm{C}$ annealing step for $30 \mathrm{~s}$, and an extension step of $72^{\circ} \mathrm{C}$ for $45 \mathrm{~s}$; followed by a final extension at $72^{\circ} \mathrm{C}$ for $7 \mathrm{~min}$. The specificity of the fungal and barley primers and probes was confirmed on the standards through qPCR. This was accomplished by running the markers with their corresponding template DNA, with the opposite DNA, and as a multiplex reaction with both barley and fungal DNA present to insure that no reaction inhibition or nonspecific amplification occurred. All qPCR reactions were performed in a Bio-Rad Laboratories C1000 thermocycler with an attached CFX96 real-time PCR detection system (Bio-Rad Laboratories, Hercules, CA) utilizing the following protocol: denaturation of $95^{\circ} \mathrm{C}$ for $3 \mathrm{~min}$ followed by 40 cycles of $15 \mathrm{~s}$ of denaturation at $95^{\circ} \mathrm{C}$ and a $1 \mathrm{~min}$ annealing step at $60^{\circ} \mathrm{C}$. The reactions were optimized to a volume of $25 \mu \mathrm{l}$ in clear 96-well PCR plates (Bio-Rad Laboratories) using iQ multiplex powermix (BioRad Laboratories), with each reaction containing 8.75 pmol of each ubiquitin primer and probe and $5 \mathrm{pmol}$ of each fungal primer and probe. The efficiency (efficiency $=10^{(-1 / \text { slope })}-1$ ) of the experiment was then calculated to determine multiplex suitability and repeatability (8).

The samples for each time point were run in replicate using the previously mentioned conditions and the assay was repeated twice. Each assay consisted of the samples from one time point and the standards. Samples where quantification cycle $(\mathrm{Cq})$ values were greater than 37 or where $\mathrm{Cq}$ values for a primer set differed by more than one cycle between replicates within an assay were removed from analysis. The varieties were evaluated by subtracting the $\mathrm{Cq}$ value of the barley hydrolysis probe from the $\mathrm{Cq}$ value of the fungal hydrolysis probe for each sample to normalize for the amount of barley tissue present. A Shapiro-Wilk test was used to establish population normality at each time point followed by an analysis of variance (ANOVA) for the cultivars and line to determine whether 
statistical differences were observed. Tukey's honest significant difference test was performed to establish statistical differences between cultivars and provide a ranking from most to least amount of fungal DNA present. All statistical analysis was performed using JMP 10.0 (SAS Institute, Cary, NC).

Evaluation of stem rust infection progression via fluorescence microscopy. Twelve $2-\mathrm{cm}$ tissue segments from the center of the primary leaf were collected for each barley genotype at each time point. The time points 24 and 48 HPI were evaluated using a modified Uvitex 2B fluorescence microscopy protocol developed by S. Dugyala, P. Borowicz, R. Brueggeman, and $\mathrm{M}$. Acevedo (unpublished data) $(16,18,31)$. The samples were cleared in chloroform-methanol $(2: 1, \mathrm{vol} / \mathrm{vol})$ for $3 \mathrm{~h}$ at $22^{\circ} \mathrm{C}$. The chloroform-methanol solution was replaced with a lactophenolethanol $(1: 2, \mathrm{vol} / \mathrm{vol})$ solution and incubated at $70^{\circ} \mathrm{C}$ for $2 \mathrm{~min}$, then stored overnight at $22^{\circ} \mathrm{C}$. After washing in $50 \%$ ethanol twice for $15 \mathrm{~min}$, twice in $0.5 \mathrm{M} \mathrm{NaOH}$ for $15 \mathrm{~min}$, and twice in distilled water for $15 \mathrm{~min}$, samples were incubated in $0.1 \mathrm{M}$ Tris/ $\mathrm{HCl}$ buffer for $30 \mathrm{~min}$ at $22^{\circ} \mathrm{C}$ and $0.3 \%$ Uvitex $2 \mathrm{~B}$ for $5 \mathrm{~min}$ at $22^{\circ} \mathrm{C}$, then washed four times in distilled water for $10 \mathrm{~min}$. The multiple wash steps were followed by incubating the samples in $25 \%$ glycerol for $20 \mathrm{~min}$ at $22^{\circ} \mathrm{C}$ and then storing them in $50 \%$ glycerol at $4{ }^{\circ} \mathrm{C}$ in the dark until they were mounted between a glass slide and a coverslip in a lactophenol and glycerol (1:200, vol/vol) solution. All mounted tissue samples were viewed using a structured illumination technique using a Zeiss ApoTome 2 module on a Zeiss Axio Imager M2 fluorescence microscope with the BP379401 excitation filter and FT420 beam splitter (Carl Zeiss AG, Oberkochen, Germany).

\section{RESULTS}

Evaluation of stem rust infection process via qPCR assay. The primers utilized for qPCR were found to be specific and only produced amplicons from the expected DNA sources (Fig. 1). Additionally, the fungal and barley primers and probes did not perform significantly differently $(P=0.65)$ under single or multiplex conditions (Fig. 2). Cross amplification was not observed between the barley DNA and fungal primers and probes or the fungal DNA and barley primers and probes during the qPCR assay. The $\mathrm{Cq}$ values for the fungal standards ranged from $19.5 \pm 0.3$ for the $200 \mathrm{ng} / \mu \mathrm{l}$ standard to $25.7 \pm 0.4$ for the $2.47 \mathrm{ng} / \mu \mathrm{l}$ standard in the first experiment and from $21.1 \pm 0.3$ for the $200 \mathrm{ng} / \mu \mathrm{l}$ standard to $25.8 \pm 0.2$ for the $2.47 \mathrm{ng} / \mu \mathrm{l}$ standard in the second experiment. The $\mathrm{Cq}$ values for the barley standards ranged from $27.0 \pm 0.3$ for the $200 \mathrm{ng} / \mu \mathrm{l}$ standard to $32.9 \pm 0.4$ for the $2.47 \mathrm{ng} / \mu \mathrm{l}$ standard in the first experiment and from $21.1 \pm 0.3$ for the $200 \mathrm{ng} / \mu \mathrm{l}$ standard to $31.6 \pm 0.2$ for the $2.47 \mathrm{ng} / \mu \mathrm{l}$ standard in the second experiment. The average reaction efficiencies for the first experiment were 100.2 \pm 4.8 and $106.7 \pm 5.4 \%$ for the fungal and barley primer and probe combination, respectively. The average reaction efficiencies for the

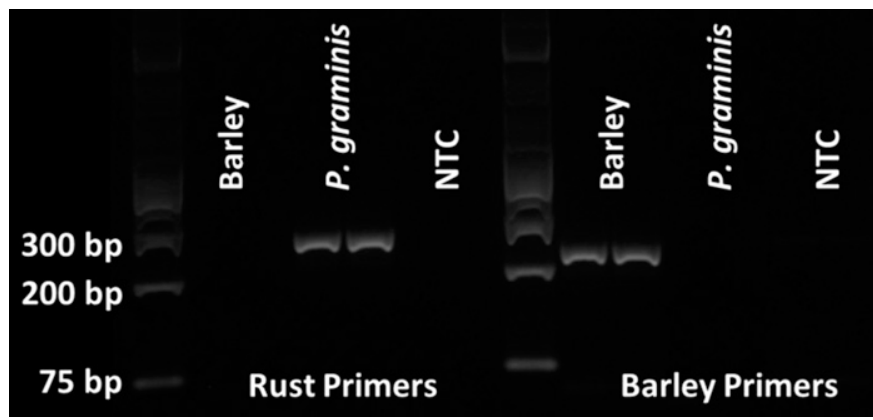

Fig. 1. Results of the specificity test of the rust primers (ITS1rustF10d and ITS1rustR3c) and the barley primers (Hvubi-F1 and Hvubi-R1). NTC = nontemplate control where water was used in place of DNA. second experiment were $100.4 \pm 6.0$ and $108.5 \pm 7.4 \%$ for the fungal and barley primer and probe combination, respectively. The priorto-inoculation time point produced fungal $\mathrm{Cq}$ values greater than 37 in all samples for both the first and second experiment. As such, 37 cycles was utilized as a cutting-off point for the presence of the pathogen, and the prior-to-inoculation time points were excluded from further analysis. In addition to the control time point, 20 data points $(6.25 \%)$ from the first experiment and 51 data points $(15.94 \%)$ from the second experiment were removed due to $\mathrm{Cq}$ values differing by more than one for intra-assay replicates or for $\mathrm{Cq}$ values of one of the primers being greater than 37. The ShapiroWilk test established that a normal distribution was present for each population at each time point. The ANOVA analysis showed significant differences $(P<0.05)$ for the barley varieties at each time point for both the first and second experiment (Table 2). During the first experiment, at the 48 HPI time point, the least amount of fungal DNA was present on resistant Beacon followed by the traditionally susceptible Steptoe, and the largest amount of fungal DNA was present on the highly resistant Q21861. This hierarchal order changed by the 12 DPI time point and susceptible Steptoe had the most fungal DNA and resistant Morex and Q21861 had the least fungal DNA. A similar pattern was observed for the second experiment. At the 48 HPI time point, the least amount of fungal DNA was detected on susceptible Steptoe and the most was detected on resistant Chevron and Q21861. The hierarchal ordering change observed in the first experiment was also observed in the second experiment by the 6 DPI time point. The most fungal DNA was detected on susceptible Steptoe and the least amount of fungal DNA was found on resistant Morex, Chevron, and Q21861.

Evaluation of stem rust infection process via fluorescence microscopy. Phenotypic differences at the microscopic level, including timing of pathogen structure development, number of established infection points, and host resistance responses, were observed among cultivars. For each sample, 100 infection sites were observed for each sample at the 24 and 48 HPI time points. At 24 HPI, appressoria were observed on Steptoe while both appressoria and haustorial mother cells (HMC) were observed on Morex, Beacon, Chevron, and Q21861 (Fig. 3). By 24 HPI, 100\% of the observed $P$. graminis spores had formed appressoria and $20 \%$ formed substomatal vesicles for Steptoe. The $P$. graminis growth had progressed further in the infection process by 24 HPI in all Rpg1containing varieties. HMC were observed for $80,100,90$, and $70 \%$ of the $P$. graminis spores inoculated on Beacon, Morex, Chevron, and Q21861, respectively. Necrosis associated with a hypersensitive response was observed for Chevron and Q21861 at 48 HPI. At 48 HPI, HMC were formed for $30 \%$ of the P. graminis infection sites

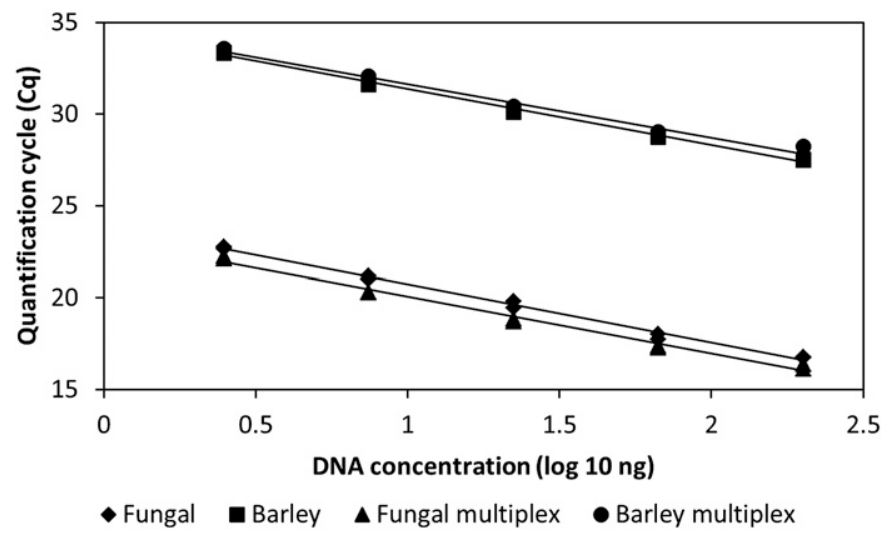

Fig. 2. Efficiency curves for the fungal and barley DNA standards under single and multiplex conditions. Fungal: $y=-3.173 x+23.907, R^{2}=0.993$, efficiency $=$ $106.6 \%$; Fungal multiplex: $y=-3.101 x+23.164, R^{2}=0.989$, efficiency $=$ 110.1\%; Barley: $y=-3.060 x+34.424, R^{2}=0.997$, efficiency $=112.2 \%$; and Barley multiplex: $y=-2.929 x+34.549, R^{2}=0.991$, efficiency $=119.5 \%$. 
inoculated on Steptoe, $80 \%$ for Beacon, and 100\% for Morex, Chevron, and Q21861.

Phenotypic evaluation. During the phenotypic evaluation of experiment 1 , the lowest infection type observed was a 0 ; and the highest was a $3+$ (Table 2). Susceptible Steptoe's infection type ranged from 3 to $3+$. The infection types of the resistant Beacon, Morex, and Q21861 ranged from 12 to 2, 12 to 2, and 0 ; to ;1-, respectively. During the evaluation of experiment 2, the lowest infection type observed was a 0 ; and the highest was a $3+$ (Table 2). Infection types of Steptoe ranged from 3- to 3+, Beacon from 12 to 2, Morex from 12 to 21, and Q21861 from 0 ; to ; 1 -. All Chevron individuals presented with a mesothetic reaction $(\mathrm{X})$ that included the infection types $0 ;, 1$, and 2 in both experiments 1 and 2 .

\section{DISCUSSION}

The qPCR assay reported in the current study was shown to effectively separate cultivars by the relative amounts of fungal DNA at early stages of the infection process. The hierarchal order produced by the analysis method at 24 and 48 HPI was not the same as the order by the level of resistance determined using the traditional phenotyping methodology at 12 DPI. However, the qPCR assay demonstrated similarity to qualitative microscopic observations a 48 HPI, allowing for early phenotyping and the ability to separate temporal differences in resistance responses.

The phenotyping at 12 DPI was consistent with what has been previously reported for all of the lines except Chevron $(22,34)$. Chevron has been previously reported to have an infection type that ranges between 0 ; to 1 ; when inoculated with race MCC. It is unknown why Chevron displayed a mesothetic reaction; however, the infection types observed were consistent between experiments 1 and 2 in the present study. It is possible that there are virulence differences between the MCCFC isolate used in the current study and the MCC isolates used in previous studies which affect Chevron's infection type. At 12 DPI, the qPCR assay was able to distinguish susceptible Steptoe from the resistant cultivars and lines; however, the hierarchal ordering of resistant cultivars for the qPCR assay and the order based solely on infection types was not the same. This lack of similarity may be due to the qPCR assay being able to account for additional components of resistance and the nature of the stem rust infection process such as disease severity, infection efficiency (receptivity), mycelial growth, latent period, and aggressiveness of the pathogen $(12,24,35,40)$. The ability to differentiate these components may lead to the identification and incorporation of underutilized and underappreciated resistance mechanisms.

The ability to phenotype barley at early time points can provide new and useful information toward understanding the mechanisms involved in stem rust resistance. Upon completion of the first experiment, the time point of 24 HPI was added to determine whether statistical differences could be detected earlier than $48 \mathrm{HPI}$. It was found that the hierarchal order of the 24 HPI time point was similar to that of the 0 HPI time point in the second experiment because statistical differences were observed between the cultivars at 0 HPI (Table 2). Furthermore, this ordering did not correlate with the microscopic observations at $24 \mathrm{HPI}$. These variations may be due to the number of spores on the leaf surface or the amount of leaf tissue present and suggests that the qPCR assay may not be sensitive or accurate enough at very low levels of fungal DNA in planta.

In barley, the most well-characterized resistance gene to wheat stem rust is Rpgl (7,21-23). The phosphorylation of Rpgl has been shown to occur within 5 min of spore contact with the leaf when inoculated with $P$. graminis f. sp. tritici race MCC $(22,23)$. The early phosphorylation in response to spore contact suggests the Rpg1-mediated resistance response would be a pre-haustorial resistance response $(20,41)$. Microscopic observations in the present study, however, show that necrosis occurs between 24 and 48 HPI in Rpgl-containing varieties after the formation of HMC within the first $24 \mathrm{HPI}$. As such, the Rpgl-mediated resistance pathway does not appear to impede the formation of haustoria. Furthermore, the evidence presented by Nirmala et al. (21) supporting Rpgl phosphorylation and subsequent degradation prior to the 24 HPI time point suggests that early spore detection may prime the later post-haustorial formation defense response. Thus, Rpg1-mediated resistance may involve both pre- and posthaustorial components.

Interestingly, in the current study, susceptible Steptoe displayed greater resistance to $P$. graminis race MCCFC at both 24 and 48 HPI compared with the varieties containing known stem rust resistance genes. As a susceptible cultivar, it would be expected that fungal growth and structural development would occur at a greater rate on Steptoe than on resistant cultivars. However, at 24 and 48 HPI, the fungal development in Steptoe was delayed, indicating that there may be a minor gene or genes providing a stronger initial resistance than the barley varieties containing Rpg 1 and $r p g 4 / R p g 5$. This basal resistance could be provided via physiological differences in the leaf epidermal chemistry of Steptoe. Variations of cuticle surface chemistry between cultivars have been shown to have an effect on the infection process of Blumeria graminis (DC) Speer f. sp. hordei on barley and B. graminis (DC) Speer f. sp. tritici on wheat (43). Surface topology and chemistry have also been shown to play important roles in inducing the formation of appressoria for P. graminis f. sp. tritici $(10,28)$. Conversely, the resistance may be provided by a minor-effect resistance gene or a minor-effect gene that provides an additive effect to other resistance genes. Two minor additive effect stem rust resistance QTL have been previously identified in barley. Both of these QTL were located on chromosome $2 \mathrm{H}$; one was identified in Morex by Druka et al. (13) and the other identified in SM89010 by Moscou et al. (19). Both QTL were identified via expression (e)QTL methodology and do not appear to provide resistance while unaccompanied by a major-effect resistance gene such as Rpgl or rpg4/Rpg5. The eQTL identified by Druka et al. (13) was mapped using the Steptoe/Morex double haploid population and found to be conferred by Morex. The eQTL in Morex was identified using mRNA from noninoculated plants, which would only allow for identification of genes that are constitutively expressed. Furthermore, the eQTL was detected using the infection type 12 to 14

TABLE 2. Comparison of mean relative fungal DNA in planta for each time point and the observed median infection type (IT) for each barley genotype during the two experiments ${ }^{\mathrm{z}}$

\begin{tabular}{|c|c|c|c|c|c|c|c|c|c|c|}
\hline \multirow[b]{2}{*}{ Cultivar or line } & \multicolumn{5}{|c|}{ Experiment 1} & \multicolumn{5}{|c|}{ Experiment 2} \\
\hline & $0 \mathrm{HPI}$ & $48 \mathrm{HPI}$ & 6 DPI & $12 \mathrm{DPI}$ & IT & $0 \mathrm{HPI}$ & $24 \mathrm{HPI}$ & 48 HPI & 6 DPI & IT \\
\hline Steptoe & $2.64 \mathrm{a}$ & $2.23 \mathrm{~b}$ & $0.93 \mathrm{a}$ & $-7.13 \mathrm{c}$ & 3 & $2.51 \mathrm{a}$ & $1.70 \mathrm{ab}$ & $1.16 \mathrm{a}$ & $-6.02 \mathrm{c}$ & 3 \\
\hline Beacon & $3.29 \mathrm{a}$ & $4.96 \mathrm{a}$ & $-2.22 b$ & $-4.44 b$ & 12 & $1.84 \mathrm{ab}$ & $2.15 \mathrm{a}$ & $1.04 \mathrm{ab}$ & $-4.55 b$ & 21 \\
\hline Morex & $0.76 \mathrm{~b}$ & $1.59 \mathrm{bc}$ & $1.37 \mathrm{a}$ & $-0.54 \mathrm{a}$ & 21 & $0.94 \mathrm{c}$ & $0.59 \mathrm{c}$ & $0.24 \mathrm{bc}$ & $-1.98 \mathrm{a}$ & 12 \\
\hline Chevron & $1.5 \mathrm{ab}$ & $1.31 \mathrm{bc}$ & $-4.24 c$ & $-3.56 b$ & $X(0 ; 21)$ & $1.29 \mathrm{bc}$ & $0.86 \mathrm{bc}$ & $-0.45 \mathrm{c}$ & $-1.15 \mathrm{a}$ & $\mathrm{X}(0 ; 12)$ \\
\hline Q21861 & $0.61 \mathrm{~b}$ & $0.81 \mathrm{c}$ & $-1.46 \mathrm{~b}$ & $-1.34 \mathrm{a}$ & 0 & $2.37 \mathrm{ab}$ & $0.97 \mathrm{bc}$ & $-0.31 \mathrm{c}$ & $-3.05 \mathrm{a}$ & 0 \\
\hline
\end{tabular}

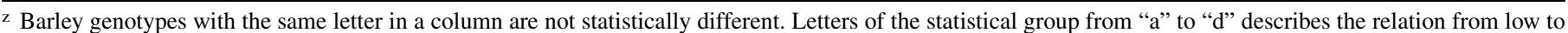
high amounts of fungal DNA relative to host DNA. The time point $0 \mathrm{~h}$ postinoculation (HPI) consists of tissue collected immediately after inoculation; DPI = days postinoculation. Mean of relative fungal DNA was calculated by subtracting the barley quantification cycle (Cq) from the fungal Cq. 
DPI, which may not allow for detection of the defense response in Steptoe observed at 24 and 48 HPI in this study. Despite the presumed presence of this resistance component gene in Steptoe, the effect is not enough to provide resistance during later stages of the infection, resulting in susceptibility at 12 DPI. Future mapping experiments will be needed to identify the gene or genes involved. The observations in the present study demonstrate the variability of resistance at different stages and the need for additional methods of evaluation to unravel the complexities of disease resistance.

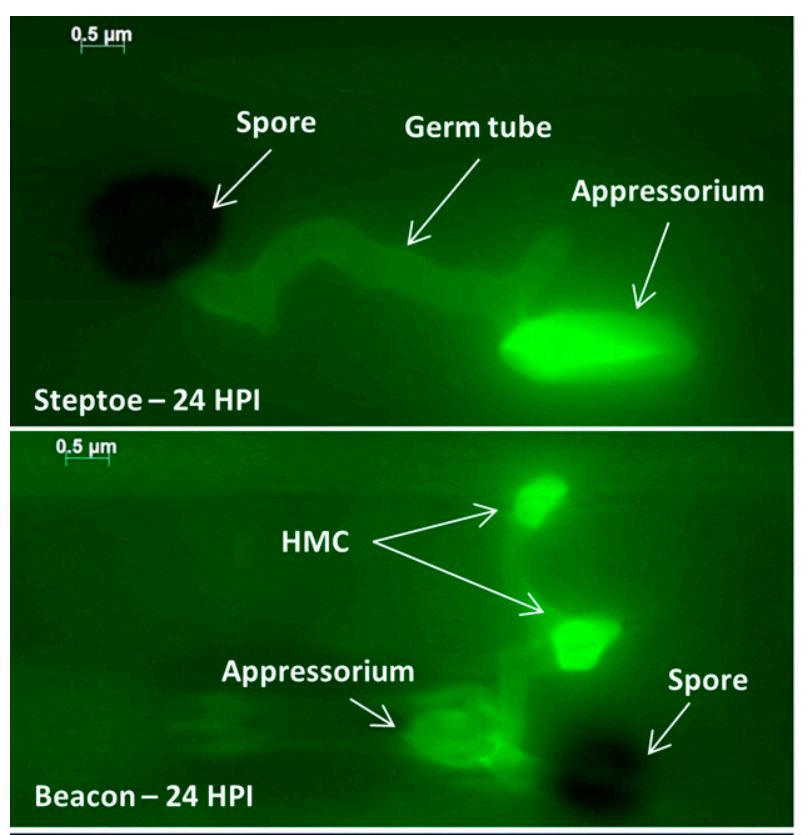

$0.5 \mu \mathrm{m}$
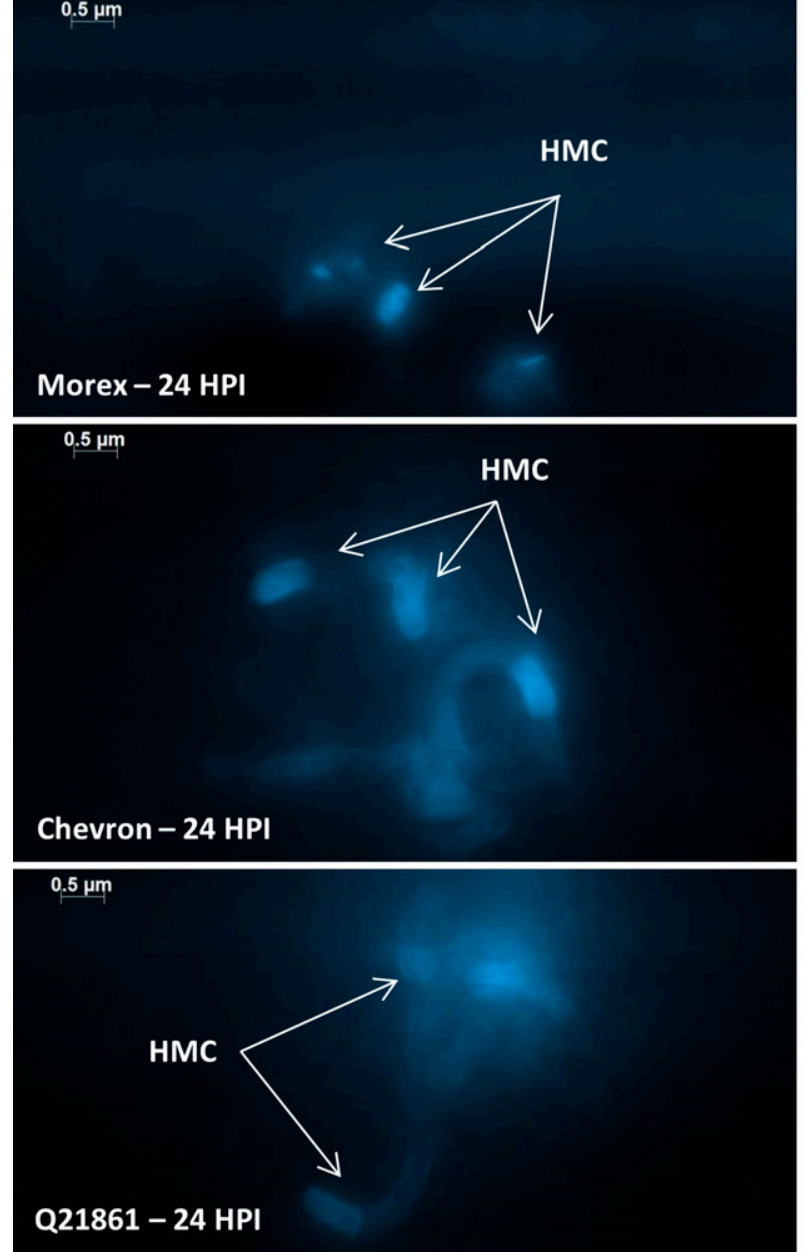

$0.5 \mu \mathrm{m}$

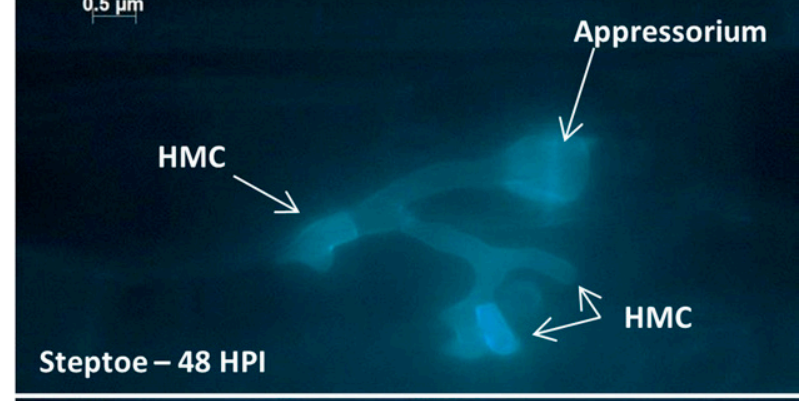

$0.5 \mu \mathrm{m}$

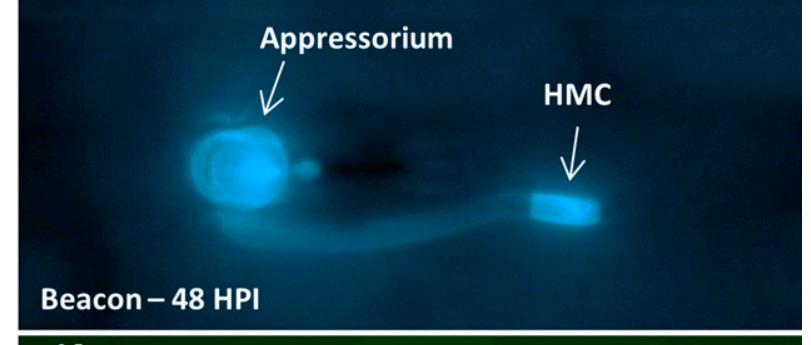

$0.5 \mu \mathrm{m}$

\section{Morex $-48 \mathrm{HPI}$}

$0.5 \mu \mathrm{m}$

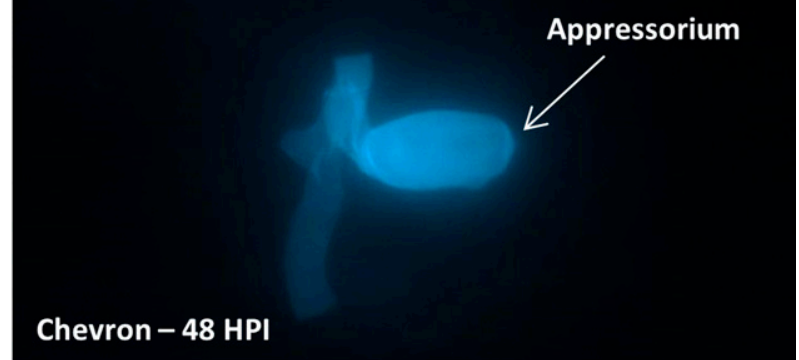

$0.5 \mu \mathrm{m}$

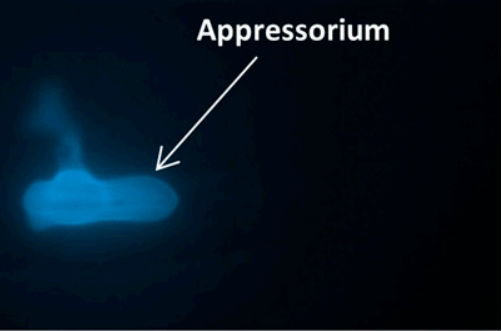

Fig. 3. Fluorescence microscopy images showing infection structure development for Puccinia graminis f. sp. tritici race MCCFC on barley. All images were taken at $\times 63$ magnification. The color of some images was adjusted to green to provide better contrast. Haustorial mother cell (HMC) development was difficult to observe for Chevron and Q21861 at $48 \mathrm{~h}$ postinoculation (HPI) due to a masking effect resulting from host necrosis. 


\section{ACKNOWLEDGMENTS}

We thank M. Breiland for his technical assistance. This research was supported, in part, through the American Malting Barley Association, the United States Department of Agriculture National Institute of Food and Agriculture through the Agriculture and Food Research Initiative Competitive Grant number 2009-65203-05696, and by the North Dakota State University Advance FORWARD program through funding provided by the National Science Foundation Grant number HRD-0811239.

\section{LITERATURE CITED}

1. Acevedo, M., Jackson, E. W., Chong, J., Rines, H. W., Harrison, S., and Bonman, J. M. 2010. Identification and validation of quantitative trait loci for partial resistance to crown rust in oat. Phytopathology 100:511-521.

2. Acevedo, M., Jackson, E., Sturbaum, A., Ohm, H., and Bonman, J. 2010. An improved method to quantify Puccinia coronate f. sp. avenae DNA in the host Avena sativa. Can. J. Plant Pathol. 32:215-224.

3. Atallah, Z., Bae, J., Jansky, S., Rouse, D., and Stevenson, W. 2007. Multiplex real-time quantitative PCR to detect and quantify Verticillium dahliae colonization in potato lines that differ in response to Verticillium wilt. Phytopathology 97:865-872.

4. Atallah, Z., and Stevenson, W. 2007. A methodology to detect and quantify five pathogens causing potato tuber decay using real-time quantitative PCR. Phytopathology 97:865-872.

5. Barnes, C., and Szabo, L. 2007. Detection and identification of four common rust pathogens of cereals and grasses using real-time polymerase chain reaction. Phytopathology 97:717-727.

6. Brueggeman, R., Rostoks, N., Kudma, D., Killan, A., Han, F., Chen, J., Druka, A., Steffenson, B., and Kleinhofs, A. 2002. The barley stem rustresistance gene Rpg1 is a novel disease-resistance gene with homology to receptor kinases. Proc. Natl. Acad. Sci. USA 99:9328-9333.

7. Brueggeman, R., Steffenson, B., and Kleinhofs, A. 2009. The rpg4/Rpg5 stem rust resistance locus in barley; resistance genes and cytoskeleton dynamic. Cell Cycle 8:977-981.

8. Bustin, S., Benes, V., Garson, J., Hellemans, J., Huggett, J., Kubista, M., Mueller, R., Nolan, T., Pfaffl, M., Shipley, G., Vandesompele, J., and Wittwer, C. 2009. The MIQE guidelines: Minimum information for publication of quantitative real-time PCR experiments. Clin. Chem. 55:611-622.

9. Chelkowski, J., Miroslaw, T., and Sobkiewicz, A. 2003. Resistance genes in barley (Hordeum vulgare L.) and their identification with molecular markers. J. Appl. Genet. 44:291-309.

10. Collins, T. J., Moerschbacher, B. M., and Read, N. D. 2001. Synergistic induction of wheat stem rust appressoria by chemical and topographical signals. Physiol. Mol. Plant Pathol. 58:259-266.

11. Derevnina, L., Fetch, T., Singh, D., Brueggeman, R., Dong, C. M., and Park, R. F. 2014. Analysis of stem rust resistance in Australian barley cultivars. Plant Dis. 98:1485-1493.

12. Díaz-Lago, J. E., Stuthman, D. D., and Leonard, K. J. 2003. Evaluation of components of partial resistance to oat crown rust using digital image analysis. Plant Dis. 87:667-674.

13. Druka, A., Potokina, E., Luo, Z., Bonar, N., Druka, I., Zhang, L., Marshall, D. F., Steffenson, B. J., Close, T. J., Wise, R. P., Kleinhofs, A., Williams, R. W., Kearsey, M. J., and Waugh, R. 2008. Exploiting regulatory variation to identify genes underlying quantitative resistance to the wheat stem rust pathogen Puccinia graminis f. sp. tritici in barley. Theor. Appl. Genet. 117:261-272.

14. Hu, J., Johnson, E. G., Wang, N., Davoglio, T., and Dewdney, M. M. 2014. qPCR quantification of pathogenic Guignardia citricarpa and nonpathogenic G. mangiferae in citrus. Plant Dis. 98:112-120.

15. Jackson, E., Avant, J., Overturf, K., and Bonman, J. 2006. A quantitative assay of Puccinia coronate f. sp. avenae DNA in Avena sativa. Plant Dis. 90:629-636.

16. Kuck, K. H., Tiburzy, R., Hänssler, G., and Reisener, H. J. 1981. Visualization of rust haustoria in wheat leaves by using fluorochromes. Physiol. Plant Pathol. 19:439-441.

17. Leonard, K., and Szabo, L. 2005. Stem rust of small grains and grasses caused by Puccinia graminis. Mol. Plant Pathol. 6:99-111.

18. Moldenhauer, J., Moerschbacher, B. M., and van der Westhuizen, A. J. 2006. Histological investigation of stripe rust (Puccinia striiformis $\mathrm{f}$. $\mathrm{sp}$. tritici) development in resistant and susceptible wheat cultivars. Plant Pathol. 55:469-474.

19. Moscou, M. J., Lauter, N., Steffenson, B., and Wise, R. P. 2011. Quantitative and qualitative stem rust resistance factors in barley are associated with transcriptional suppression of defense regulons. PLoS Genet. 7:e1002208.

20. Niks, R. E., and Dekens, R. G. 1991. Prehaustorial and posthaustorial resistance to wheat leaf rust in diploid wheat seedlings. Phytopathology $81: 847-851$.
21. Nirmala, J., Dahl, S., Steffenson, B., Kannangara, C., von Wettstein, D., Chen, X., and Kleinhofs, A. 2007. Proteolysis of the barley receptor-like protein kinase Rpgl by a proteasome pathway is correlated with Rpg1mediated stem rust resistance. Proc. Natl. Acad. Sci. USA 104: 10276-10281.

22. Nirmala, J., Drader, T., Chen, X., Steffenson, B., and Kleinhofs, A. 2010. Stem rust spores elicit rapid Rpg1 phosphorylation. Mol. Plant-Microbe Interact. 23:1635-1642.

23. Nirmala, J., Drader, T., Lawrence, P. K., Yin, C., Hulbert, S., Steber, C. M., Steffenson, B. J., Szabo, L. J., von Wettstein, D., and Kleinhofs, A. 2011. Concerted action of two avirulent spore effectors activates Reaction to Puccinia graminis 1 (Rpg1)-mediated cereal stem rust resistance. Proc. Natl. Acad. Sci. USA 108:14676-14681.

24. Parlevliet, J. E. 1985. Resistance of the non-race-specific type. Pages 501-525 in: The Cereal Rusts: Vol. II Disease, Distribution, Epidemiology, and Control. A. P. Roelfs and W. R. Bushnell, eds. Academic Press, Orlando, FL.

25. Pasche, J. S., Mallik, I., Anderson, N. R., and Gudmestad, N. C. 2013. Development and validation of a real-time PCR assay for the quantification of Verticillium dahliae in potato. Plant Dis. 97:608-618.

26. Pretorius, Z. A., Singh, R. P., Wagoire, W. W., and Payne, T. S. 2000. Detection of virulence to wheat stem rust resistance gene Sr31 in Puccinia graminis f. sp. tritici in Uganda. Plant Dis. 84:203.

27. Rashed, A., Workneh, F., Paetzold, L., Gray, J., and Rush, C. M. 2014. Zebra chip disease development in relation to plant age and time of 'Candidatus Liberibacter solanacearum' infection. Plant Dis. 98:24-31.

28. Read, N. D., Kellock, L. J., Collins, T. J., and Gundlach, A. M. 1997. Role of topography sensing for infection-structure differentiation in cereal rust fungi. Planta 202:163-170.

29. Roelfs, A. 1982. Effects of barberry eradication on stem rust in the United States. Plant Dis. 66:177-181.

30. Rohringer, R., Kim, W. K., and Samborski, D. J. 1979. A histological study of interactions between avirulent races of stem rust and wheat containing resistance genes $\operatorname{Sr} 5$, Sr6, Sr8, or Sr22. Can. J. Bot. 57:324-331.

31. Rohringer, R., Kim, W. K., Samborski, D. J., and Howes, N. K. 1977. Calcofluor: An optical brightener for fluorescence microscopy of fungal plant parasites in leaves. Phytopathology 67:808-810.

32. Rostoks, N., Schmierer, D., Kudrna, D., and Kleinhofs, A. 2003. Barley putative hypersensitive induced reaction genes: Genetic mapping, sequence analyses and differential expression in disease lesion mimic mutants. Theor. Appl. Genet. 107:1094-1101.

33. Stakman, E. C., Stewart, D. M., and Loegering, W. Q. 1962. Identification of physiologic races of Puccinia graminis var. tritici. U.S. Dep. Agric. Agric. Res. Serv. E-617.

34. Steffenson, B. J. 1992. Analysis of durable resistance to stem rust in barley. Euphytica 63:153-167.

35. Steffenson, B. J., and Wilcoxson, R. D. 1987. Receptivity of barley to Puccinia graminis f. sp. tritici. Can. J. Plant Pathol. 9:36-40.

36. Steffenson, B. J., Wilcoxson, R. D., and Roelfs, A. P. 1985. Resistance of barley to Puccinia graminis f. sp. tritici and Puccinia graminis f. sp. secalis. Phytopathology 75:1108-1111.

37. Steffenson, B. J., Zhou, H., Chai, Y., and Grando, S.2012. Vulnerability of cultivated and wild barley to African stem rust race TTKSK. Pages 149-155 in: Advances in Barley Science: Proc. 11th Int. Barley Genet. Symp. C. Li, G. Zhang, and X. Liu, eds. Zhejiang University Press, Hangzhou.

38. Stewart, N., and Via, L. 1993. A rapid CTAB DNA isolation technique useful for RAPD fingerprinting and other PCR applications. Biotechniques 14:748-749.

39. Sun, Y., and Steffenson, B. J. 2005. Reaction of barley seedlings with different stem rust resistance genes to Puccinia graminis f. sp. tritici and Puccinia graminis f. sp. secalis. Can. J. Plant Pathol. 27:80-89.

40. Tiburzy, R., Noll, U., and Reisener, H. J. 1990. Resistance of wheat to Puccinia graminis f. sp. tritici: Histological investigation of resistance caused by the $\operatorname{Sr} 5$ gene. Physiol. Mol. Plant Pathol. 36:95-108.

41. Vaz Patto, M. C., Fernández-Aparicio, M., Moral, A., and Rubiales, D. 2009. Pre and posthaustorial resistance to rusts in Lathyrus cicero L. Euphytica 165:27-34.

42. Wang, X., McCallum, B. D., Fetch, T., Bakkeren, G., Marais, G. F., and Saville, B. J. 2013. Comparative microscopic and molecular analysis of Thatcher near-isogenic lines with wheat leaf rust resistance genes $\operatorname{Lr} 2 a$, $L r 3, L r B$, or $\operatorname{Lr} 9$ upon challenge with different Puccinia triticina races. Plant Pathol. 62:698-707.

43. Yang, S. L., and Ellingboe, A. H. 1972. Cuticle layer as a determining factor for the formation of mature appressoria of Erysiphe graminis on wheat and barley. Phytopathology 62:708-714.

44. Zhang, L., Fetch, T., Nirmala, J., Schmierer, D., Brueggeman, R., Steffenson, B., and Kleinhofs, A. 2006. Rprl, a gene required for Rpg1dependent resistance to stem rust in barley. Theor. Appl. Genet. 113: 847-855. 